\title{
An Improved Process for the Preparation of an $\alpha, \alpha$-Difluorosulfonylisoxazoline Herbicide
}

\author{
Chantal Belie ${ }^{a}$, Jutta Boehmera, Eric Clarkea, Anne Dalençon ${ }^{a}$, Jonathan Dallimore ${ }^{a}$, \\ Martin Diggelmann ${ }^{\star b}$, Myriem El Qacemicd, Katharine Ingrama, Andy Knee ${ }^{a}$, Tony Kozakiewicz ${ }^{a}$, \\ Adrian Longstaffa , Derek McCormack ${ }^{\mathrm{a}}$, Matthew McLachlan ${ }^{\mathrm{a}}$, Nick Mulholland ${ }^{\mathrm{a}}$, Andrew Plant ${ }^{\mathrm{b}}$, \\ and John Williams ${ }^{a}$
}

\begin{abstract}
An efficient synthesis of a difluorosulfone-containing herbicide has been achieved by selective reductive silylation of a symmetrical bis(trifluoromethyl)-1,2,3-triazole. Subsequently, a fluoride-induced reaction led to a difluoromethyl anion equivalent, which was reacted with a sulfur electrophile leading ultimately to the key difluorosulfide moiety.
\end{abstract}

Keywords: Defluorinative silylation · Herbicide · Process chemistry

Sulfonyl isoxazolines such as pyroxasulfone (KIH-485) and fenoxasulfone $(\mathrm{KIH}-1419)^{[1]}$ represent a new class of herbicides. These chemicals, which are potent inhibitors of plant Very Long Chain Fatty Acid Elongases (VLCFAEs), control weeds which would otherwise have a negative impact on crop yields.

At Syngenta, we became interested in fluorinated derivatives of this class, which showed interesting activity against grasses and broad leaf weeds. Compound $\mathbf{A}^{[2]}$ was a lead molecule in our investigation (Fig. 1) and we present here our work towards a convergent, scalable and cost-effective route to this compound.

The original research route to compound A consisted of an eight-step linear sequence and suffered from various drawbacks, not least a) the alkylation of an early triazole intermediate $\mathbf{B}$ that proceeded with poor regioselectivity; b) an electrophilic fluorination using $N$-fluorobenzenesulfonimide (NFSI), a costly reagent not well suited to our purposes (Scheme 1).

We therefore sought a new highly convergent and regioselective route to compound $\mathbf{A}$ that would use only cheap and atom-economic sources of fluorine.

${ }^{\star}$ Correspondence: Dr. M. Diggelmann ${ }^{\mathrm{b}}$

asyngenta Crop Protection

Jealott's Hill International Research Centre Bracknell

Berkshire RG42 6EY, UK

'Syngenta Crop Protection AG

$\mathrm{CH}-4002$ Basel, Switzerland

'Syngenta Crop Protection Münchwilen AG

Schaffhauserstrasse, $\mathrm{CH}-4332$ Stein, Switzerland

${ }^{\mathrm{d} C}$ Correspondence should be addressed to Dr. M. El

Qacemi

Tel.: +4162 8660231

E-mail: myriem.el_qacemi@syngenta.com

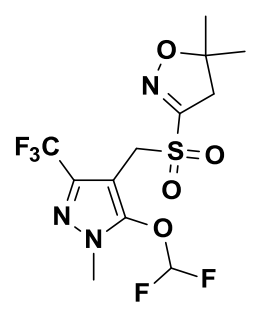

Pyroxasulfone $(\mathrm{K} H-485)$

Fenoxasulfone (KIH-1419)

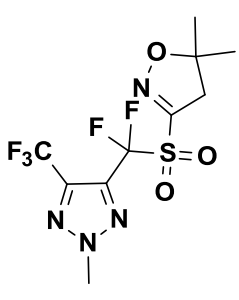

Fig. 1. Representatives of a new class of herbicides.

a) triazole alkylation

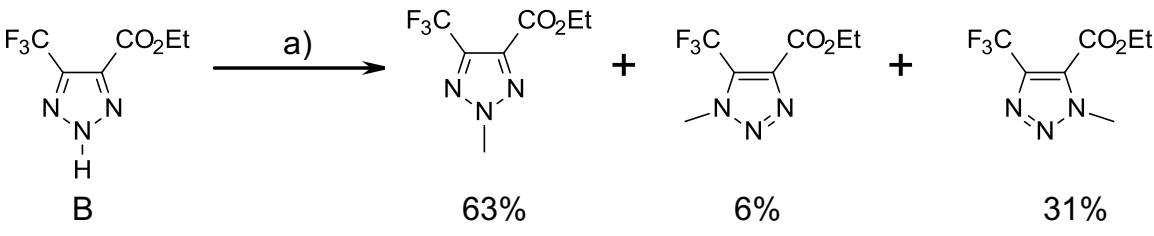

conditions: a) $\mathrm{K}_{2} \mathrm{CO}_{3}$, $\mathrm{Mel}, \mathrm{MeCN}$;

b) electrophilic fluorination<smiles>Cn1nc(C[SH](=O)(O)C2=NOC(C)(C)C2)c(C(F)(F)F)n1</smiles><smiles>[I-][I-]</smiles>

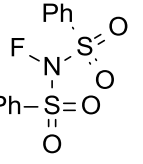

$\mathrm{NFSI}$

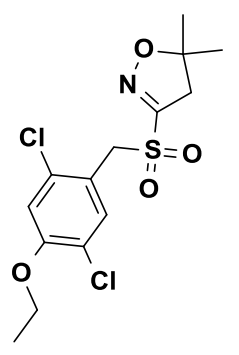

Compound A conditions: b) LiHMDS, DCM, $-30^{\circ} \mathrm{C}, 70 \%$ yield

Scheme 1. Challenges in the initial research route. 


\section{The First Convergent Synthesis to Compound A}

Our preferred retrosynthetic strategy focussed on the formation of the compound A bridge by addition of a "difluoromethyl anion' equivalent to a suitable sulfur-based electrophile (Scheme 2).

The literature precedent for a coupling of this type was encouraging, with a publication from Wakselman et al. ${ }^{[3]}$ highlighting the formation of phenyldifluoromethyl silane (2) by reductive silylation of phenyldifluorochloromethane (1) ${ }^{[4]}$ and subsequent reaction of the silane with a range of electrophiles (Scheme 3).

We envisaged that, in our case, the key substrate for the reductive silylation, the difluorochlorotriazole 7 , could be prepared from the trichlorotriazole $\mathbf{6}$, which in turn could be derived from either the bromotriazole $\mathbf{4}$ or the carboxylic acid 5 (Scheme 4). ${ }^{[5]}$

Starting from the bromotriazole $\mathbf{4}$, halogen/metal exchange with the 'turbo Grignard' reagent iPrMgCl$\cdot \mathrm{LiCl}$, followed by reaction with $\mathrm{CCl}_{4}$ afforded the desired product 6 in $65 \%$ yield albeit with significant quantities of the corresponding chlorotriazole as byproduct. More usefully, we were able to prepare $\mathbf{6}$ in larger quantities from the corresponding carboxylic acid $\mathbf{5}$ by treatment with $\mathrm{PhP}(\mathrm{O}) \mathrm{Cl}_{2}$ and $\mathrm{PCl}_{5}{ }^{.6]}$

The trichloride 6 proved to be inert to excess HF buffered with pyridine. The use of various ratios of fluorinated antimony reagents $\left(\mathrm{SbF}_{3} / \mathrm{SbCl}_{5}, \text { Swarts reaction }\right)^{[7]}$ also failed to give the desired difluorochoro compound in a clean manner, with over fluorination to the trifluoromethyl compound prevailing in all experiments attempted. In contrast, selective and clean difluorination was achieved using $\mathrm{AgBF}_{4}{ }^{[8]}$ in dichloromethane (Scheme 4) or anhydrous HF.

The final reductive silylation step worked surprisingly well given the challenging nature of this transformation. Indeed, in contrast to alkyl $\mathrm{C}-\mathrm{Cl}$ bonds, which can be reduced under standard conditions with activated magnesium, perfluorinated chloroalkyls display far reduced reactivity under similar conditions. Noteworthy, the reductive silylation of the triazole 7 represents, to the best of our knowledge, the first example of this transformation on a heteroaromatic compound.

With the key triazole 8 in hand, a range of sulfur-containing electrophiles were prepared to test their suitability in the coupling reaction. Disulfides 11 and 12, the sulfonyl derivatives $\mathbf{1 3}$ and $\mathbf{1 4}$ and the thiocyanate $\mathbf{1 5}$ (Scheme 5) were prepared from either chloroisoxazoline ${ }^{[9]} \mathbf{1 0}$ or isoxazolidinone 9. ${ }^{[10]}$

The first results obtained using disulfides were very encouraging and the

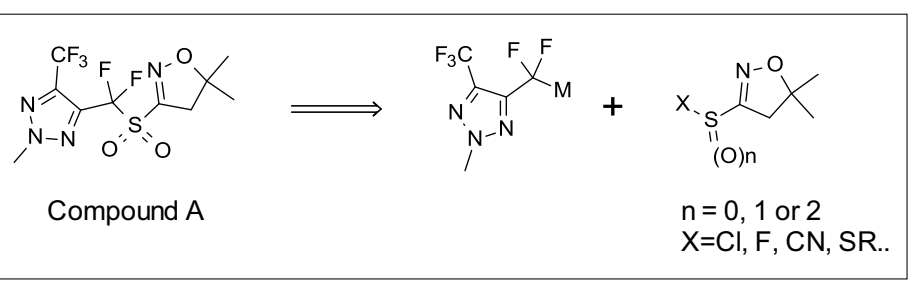

Scheme 2.

Retrosynthetic disconnection.

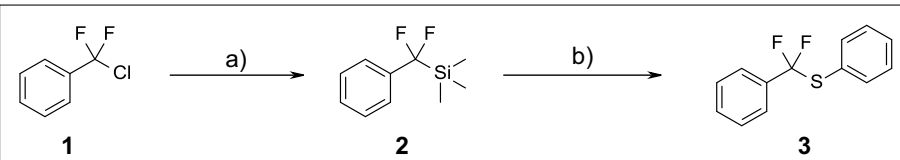

Scheme 3. Literature precedent.

conditions: a) Mg, TMSCI, DMF, 98\%; b) diphenyl disulfide, $\mathrm{KF}$, DMF, $83 \%$

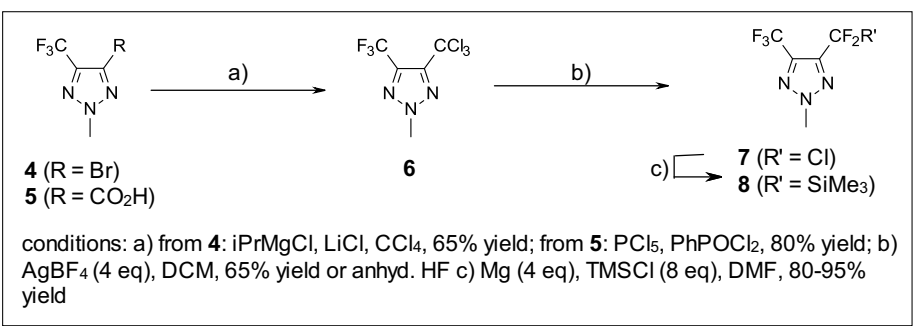

Scheme 4.

Preparation of the triazole building block.

desired compound $\mathbf{1 6}$ could be detected (Scheme 6). However, the use of the disulfide 11 involves the loss of one isoxazoline moiety, which, though potentially recyclable, is not attractive from a cost point of view. To overcome this issue, a single experiment with the mixed disulfide $\mathbf{1 2}$ was carried out. Unfortunately, under the conditions tried, the major product of the reaction was compound 17 , which probably reflects the polarisation of the $\mathrm{S}-\mathrm{S}$ bond.

Of the other electrophiles investigated (Scheme 7), the thiocyanate $\mathbf{1 5}$ emerged as the most promising coupling partner. All others either suffered from poor mass economy or selectivity in the reaction and further optimisation of the coupling reaction with $\mathbf{1 5}$ was therefore carried out (Table 1).

Initial reactions on a small scale were frequently performed with TASF (tris(dimethylamino)sulfonium difluorotrimethylsilicate) as a convenient source of anhydrous fluoride. However, a screen of different nucleophilic initiators showed that the scope was broad (including $t \mathrm{BuOK}$ and $\mathrm{CN}^{-}$) and that $\mathrm{KF}$ was optimal. Additionally, while the reaction could be performed with catalytic quantities of $\mathrm{KF}$ (reaction propagated by $\mathrm{CN}^{-}$), the reaction proceeded in higher yields with stoichiometric amounts. Polar aprotic solvents were found to be optimal, with the best result observed in DMA. The poor solubility of KF was alleviated by introduction of 10 mol\% 18-crown-6, which significantly enhanced the reaction rate.

This key reaction established the desired $\alpha, \alpha$-difluorosulfide bond and with

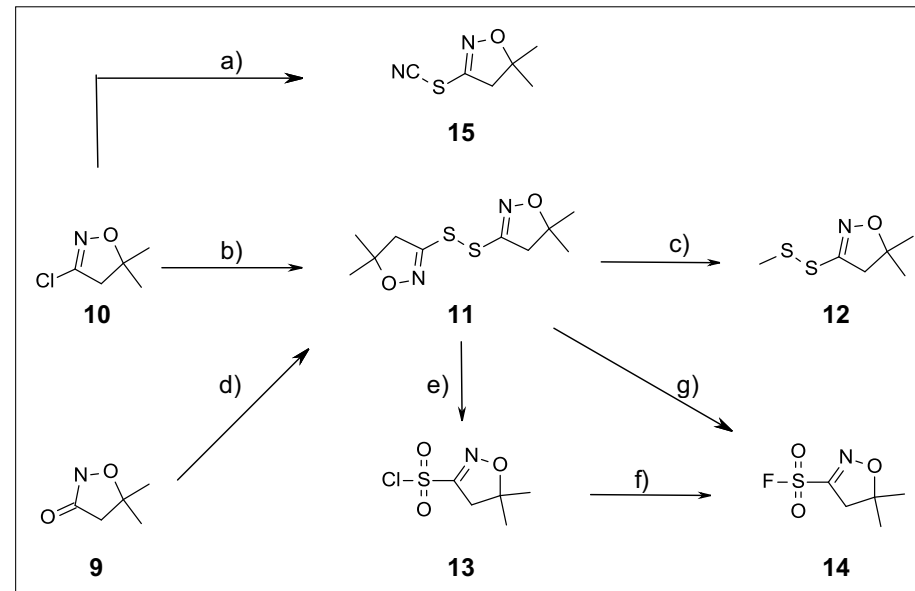

Scheme 5.

Preparation of isoxazolines synthons. 


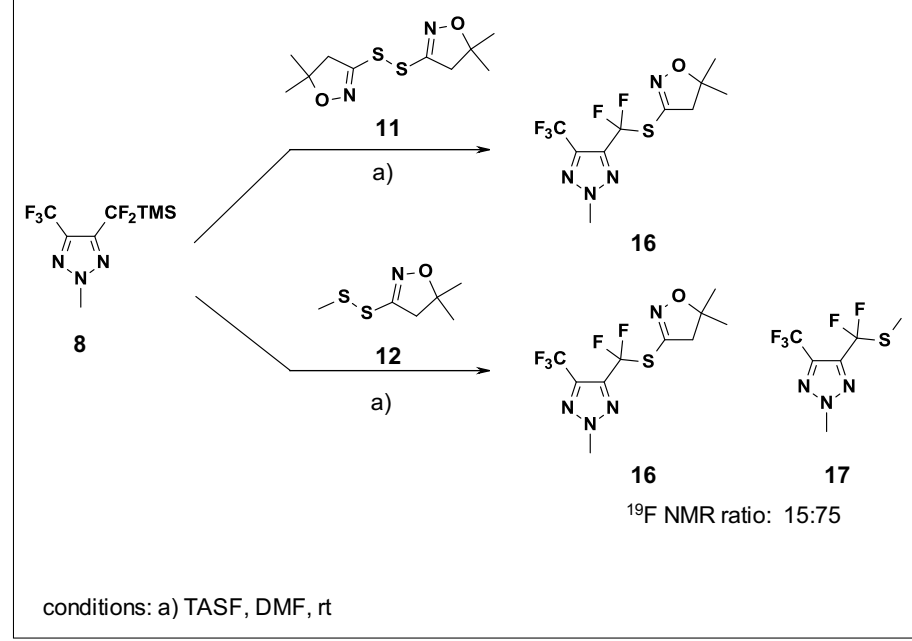

Scheme 6. First addition reactions.

Table 1.

\section{Isoxazoline reactant}

13

14

15

15

15 conditions

TASF, DMF, rt

$\mathrm{KF}$ ( 0.9 equiv), DMF, $\mathrm{rt}$

TASF ( 0.25 equiv), DMF, rt

KF ( 1 equiv), $18-c-6$ ( 0.1 equiv), DMF, $\mathrm{rt}$

KF (1 equiv), 18-c-6 (cat.), DMA, rt

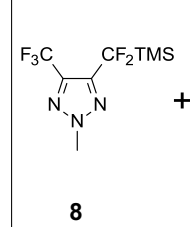

(0)n

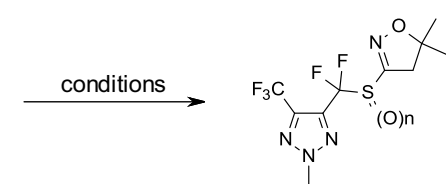

13-15

$16(\mathrm{n}=0)$

$18(n=2)=$ compound $A$

Scheme 7. Coupling step experiments. lane 8 and the starting material 20 (Fig. 3). When we initiated our investigation, only two examples of defluorinative silylation of $\mathrm{CF}_{3}$ groups were described in the literature. $[13,14]$

The required hexafluorotriazole $\mathbf{1 9}$ was prepared as reported in the literature. To our delight, it was found that the methylation proceeded with good regioselectivity to give the desired methyl triazole 20 in $87 \%$ yield.

Initial reactions suggested that the proposed reductive silylation was difficult, as only large excess of reagents (40 equiv $\mathrm{Mg}$, 8 equiv TMSCl, DMF/THF) furnished the triazole 8 in $6 \%$ yield.

However, encouraged by this result, the reaction was optimized more intensively. ${ }^{[15]}$ Most urea and amide solvents accelerated the rate of the reaction but led to lower selectivity, while ethereal solvents were far more selective but the reaction was then extremely sluggish. To improve the rate of

aDecomposition of the sulfonyl chloride $\mathbf{1 3}$ under the reaction conditions to give the chloroisoxazolin ${ }^{\mathrm{b}}$ The nucleophilic attack on the carbon atom of the isoxazoline was observed as a side product the optimised conditions in place, compound 16 could be obtained in $74 \%$ yield (Scheme 8). Subsequent oxidation with peracetic acid completed the sequence to give the desired compound $\mathbf{A}$.

\section{A Breakthrough Defluorinative Silylation - The Optimized Route to Compound A}

Given the success of the first coupling approach, we were keen to explore an even more efficient, albeit far more challenging, variant of this reaction (Fig. 2).

The N-H bis(trifluoromethyl) triazole 19 was known in the patent literature ${ }^{[1]}$ and accessible in only two steps from cheap starting materials. If achievable, a subsequent selective alkylation and reductive silylation would allow access to the key building block 16 in only four linear steps; a highly attractive option.

The desired transformation required the reduction of a relatively inert $\mathrm{C}-\mathrm{F}$ bond, which was expected to be difficult and we also anticipated that another major challenge would be to achieve the selective reduction of just one of the $\mathrm{C}-\mathrm{F}$ bonds. This was confirmed by cyclic voltammetry measurements which revealed similar redox potentials ${ }^{[12]}$ for both the product si-

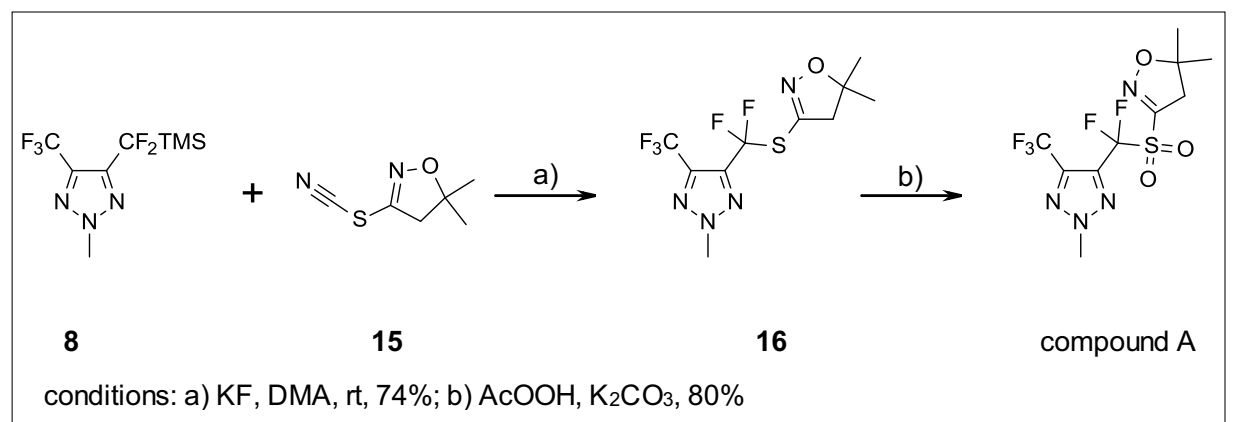

Scheme 8. Coupling step to difluorosulfide.

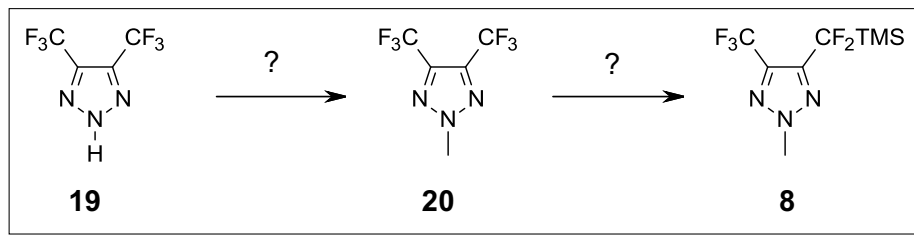

Fig. 2. Reductive silylation of $\mathrm{a}_{3}$ group.

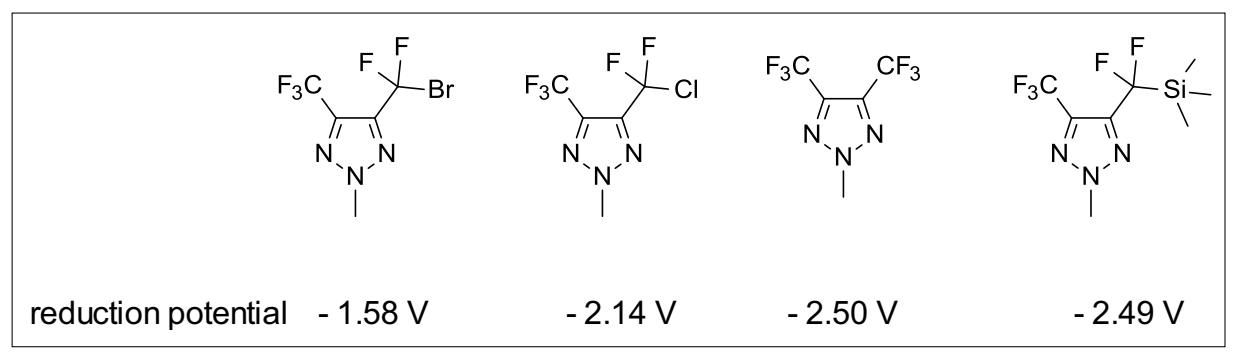

Fig. 3. Electrode reduction potentials of key triazole building blocks. 


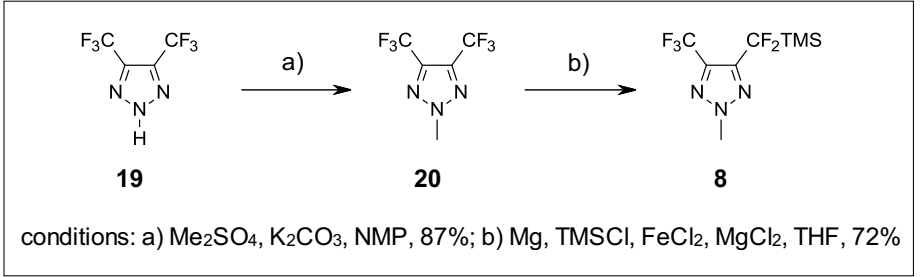

Scheme 9. Reductive silylation of the bis(trifluoromethyl) triazole.

the reaction, we thus focused our attention on THF in combination with additives, to activate the metal surface $\left(\mathrm{LiCl}, \mathrm{ZnCl}_{2}\right.$, $\mathrm{MgCl}_{2}, \mathrm{FeCl}_{2}$ and $\mathrm{FeCl}_{3}$ ), or activated forms of $\mathrm{Mg}$ (e.g. Rieke Mg).

Under the optimized conditions, a remarkable $72 \%$ yield was obtained reproducibly, using $\mathrm{Mg}$ in combination with $\mathrm{FeCl}_{2}$ and $\mathrm{MgCl}_{2}$, as additives (conditions b, Scheme 9).

In summary, a highly efficient route to compound A was developed, including a reductive silylation of a trifluoromethyl group and a convergent coupling of a 'difluoromethyl anion' equivalent and a thiocyanate. Importantly, we were able to install the difluorosulfone moiety efficiently without adding significant cost to the overall process.

\section{Experimental Part}

\subsection{Defluorinative Silylation of Compound 7 (Scheme 4)}

A suspension of magnesium powder $(1.590 \mathrm{~g}, 66 \mathrm{mmol})$ was stirred in anhydrous DMF (40 mL) under nitrogen for 90 min. To this mixture was added at room temperature chlorotrimethylsilane $(17 \mathrm{~mL}$, $135 \mathrm{mmol}$ ) and the suspension was stirred for $45 \mathrm{~min}$. To this suspension, a solution of the triazole $(3.796 \mathrm{~g}$, ca. $16.1 \mathrm{mmol})$ in anhydrous DMF $(20 \mathrm{~mL})$ was added at 0 ${ }^{\circ} \mathrm{C}$. The reaction was exothermic and some gas evolution was observed. The reaction mixture was slowly warmed to room temperature and stirred for $3.5 \mathrm{~h}$ and then quenched with ice water $(100 \mathrm{~mL})$. The solution was extracted with diethylether (3 $\times 80 \mathrm{~mL})$, washed with brine $(100 \mathrm{~mL})$, dried over $\mathrm{Na}_{2} \mathrm{SO}_{4}$ and then concentrated in vacuo to give a crude residue. This residue was filtered through a pad of silica (8:2 isohexane/ether) and concentrated to give the title compound $\mathbf{8}(4.172 \mathrm{~g}, 95 \%) .{ }^{1} \mathrm{H}$ NMR (400 MHz, $\left.\mathrm{CDCl}_{3}\right)$ : $4.24(3 \mathrm{H}) ; 0.25$ (9H) ppm. ${ }^{19} \mathrm{~F}$ NMR $\left(376 \mathrm{MHz}, \mathrm{CDCl}_{3}\right)$ : $-59.82 \mathrm{ppm}\left(\mathrm{CF}_{3}\right),-108.96 \mathrm{ppm}\left(\mathrm{CF}_{2}\right)$.

\subsection{Coupling Step Using Compound 8 (Scheme 8)}

To a solution of the thiocyanate $\mathbf{1 5}$ (680 mg, $4.39 \mathrm{mmol}$ ) under nitrogen in DMA (anhydrous) $(5.0 \mathrm{~mL})$ was added KF (spray-dried, from a new bottle, $200 \mathrm{mg}$,
$3.44 \mathrm{mmol}$ ) and 18 -crown-6. The solution turned orange immediately. The reaction mixture was stirred at room temperature for $5 \mathrm{~min}$, then a solution of the triazole 8 $(1 \mathrm{~g}, 3.66 \mathrm{mmol})$ in $1 \mathrm{ml}$ DMF was added dropwise, whereupon the solution turned brown and a slight exotherm was observed. The solution was stirred at room temperature. The reaction was followed by fluorine NMR, and was found to have gone to completion after $48 \mathrm{~h}$.

The reaction mixture was quenched with $\mathrm{NaHCO}_{3}$ and extracted with ether and washed with sat. sodium metabisulfite, then the organic layer was then dried over $\mathrm{MgSO}_{4}$ and concentrated in vacuo to give a crude residue. The residue was purified by column chromatography using $3: 1$ hexane:ether to provide the desired product $\mathbf{1 6}$ (0.9 g, 74\%). ${ }^{1} \mathrm{H}$ NMR (400 MHz, $\mathrm{CDCl}_{3}$ ): $4.31(3 \mathrm{H}, \mathrm{s}), 3.11(2 \mathrm{H}, \mathrm{s}), 1.49(6 \mathrm{H}, \mathrm{s})$ ppm. ${ }^{19} \mathrm{~F} \mathrm{NMR}\left(376 \mathrm{MHz}, \mathrm{CDCl}_{3}\right)$ : -60.08 $\left(\mathrm{CF}_{3}\right),-64.40\left(\mathrm{CF}_{2}\right)$ ppm.

\subsection{Defluorinative Silylation of Compound 20 (Scheme 9)}

A suspension of magnesium powder (251 $\mathrm{mg}, 10.3 \mathrm{mmol}$ ) and ethyl bromide (30.1 mg) was stirred in anhydrous THF $(1.45 \mathrm{~mL})$ under nitrogen for $1 \mathrm{~h}$. To this mixture was added at room temperature $\mathrm{FeCl}_{2}(16.2 \mathrm{mg})$ followed by $259 \mu \mathrm{L}$ of a solution of $\mathrm{MgCl}_{2}$ (prepared from stirring $707 \mathrm{mg}$ of $\mathrm{Mg}$ powder with $2.4 \mathrm{~g}$ of 1,2-dichloroethane in $50 \mathrm{~mL}$ of THF for 3 h). The suspension was stirred for $5 \mathrm{~min}$, and then a solution of the triazole 20 (550 $\mathrm{mg}, 87 \%$ purity) in anhydrous THF (1 $\mathrm{mL}$ ) was added, followed after $15 \mathrm{~min}$ of chlorotrimethylsilane $(1.09 \mathrm{~g})$ at $0{ }^{\circ} \mathrm{C}$. The suspension was allowed to warm to room temperature and stirred for 2 days, then the reaction was diluted with diethyl ether (10 $\mathrm{mL}$ ) and the suspension was filtered. The filtrate was concentrated under vacuum, redissolved in diethyl ether and filtered through hyflow. The filtrate obtained was concentrated under vacuum and the residue was purified by flash chromatography on silica gel (100\% hexane to 92:8 hexane/ diethylether) and concentrated to give the title compound $\mathbf{8}$ (439 mg, 73\%).

Received: April 3, 2014
[1] a) Y. Tanetani, K. Kaku, K. Kawai, T. Fujioka, T. Shimizu, Pestic. Biochem. Physiol. 2009, 95, 47; b) M. Nakatani, T. Yoshimura, R. Hanai, Y. Tanetani, T. Shimizu, 'Herbicides Disturbing the Synthesis of Very Long-Chain Fatty Acids', in 'Modern Crop Protection Compounds', 2nd Ed., Eds W. Krämer, U. Schirmer, P. Jeschke, M. Witschel, Wiley-VCH, Weinheim, 2012, Volume 1, p. 326.

[2] J. E. Boehmer, M. M. W. Mclachlan, WO Patent Appl. No. WO2007096576, 2007.

[3] J. Guidotti, F. Metz, M. Tordeux, C. Wakselman, Synlett 2004, 10, 1759.

[4] Presumably, the reaction proceeds by SET reduction of the $\mathrm{C}-\mathrm{Cl}$ bond with magnesium which rapidly reacts with $\mathrm{TMSCl}$ to give phenyldifluoromethyl silane. Attempts to isolate the organomagnesium intermediate were unsuccessful.

[5] The preparation of $\mathbf{5}$ is described in: $\mathbf{J}$. Ehrenfreund, H. Tobler, H. Walter, WO Patent Appl. No WO200418438, 2004

[6] L. H. McKendry, M. J. Ricks, R. B. Roberts, Eur. Pat. Appl. No EP0046653, 1981.

[7] a) F. Swarts, Bull. Acad. Roy. Belg. 1892, 24, 309; b) F. Swarts, Bull. Acad. Roy. Belg. 1892, 24, 474 .

[8] A. J. Bloodworth, K. J. Bowyer, J. C. Mitchell, Tetrahedron Lett. 1987, 28, 5347.

[9] M. Nakatani, K. Kaku, T. Yoshimura, M. Tamaru, H. Kawasaki, K. Kobayashi, T. Miyazawa, WO Patent Appl. No. WO2001012613, 2001.

[10] J. L. Olive, C. Petrus, F. Petrus, Bull. Soc. Chim. Fr. 1976, 9-10, 1589.

[11] a) M. Armand, Y. Choquette, M. Gauthier, C. Michot, Eur. Pat. Appl. No EP850933, 1998; b) M. Armand, C. Michot, M. Gauthier, Y. Choquette, Eur. Pat. Appl. No EP1391952, 2004.

[12] Cyclic voltammograms were obtained using a glassy carbon working electrode, $\mathrm{Ag} / \mathrm{AgCl}$ reference electrode and platinium auxiliary electrode in DMF.

[13] a) H. Amii, Y. Hatamoto, M. Seo, K. Uneyama, J. Org. Chem. 2001, 66, 7216; b) P. Clavel, M.P. Léger-Lambert, C. Biran, F. Serein-Spirau, M. Bordeau, N. Roques, H. Marzouk, Synthesis 1999, 829; c) P. Clavel, G. Lessene, C. Biran, M. Bordeau, N. Roques, S. Trévin, D. de Montauzon, J. Fluorine Chem. 2001, 107, 301.

[14] a) K. Uneyama, A. Takagi, K. Fujitani, JP Patent Appl. No. JP2008266242, 2008; b) S. Utsumi, T. Katagiri, K. Uneyama, Tetrahedron 2012, 68 , 1085 (published subsequent to our investigation in the area).

[15] Several solvents (DMA, DMF, NMP, THF TMU, DMPU, DMSO, MeCN, pyridine, $\mathrm{Et}_{2} \mathrm{O}$, TBME, dioxane), temperatures, additives $\left(\mathrm{I}_{2}\right.$, EtBr, $\mathrm{LiCl}, \mathrm{LiBr}, \mathrm{NiCl}_{2}, \mathrm{TiCl}_{4}$, TMEDA, $\mathrm{PdCl}_{2}$, $\mathrm{MgCl}_{2}, \mathrm{NaCl}, \mathrm{KF}, \mathrm{AlCl}_{3}, \mathrm{NaI} / \mathrm{NEt}_{3}$ ), activated forms of $\mathrm{Mg}$ and reducing metals $(\mathrm{Na}, \mathrm{Li} \ldots)$ were investigated. 